\title{
Durability of Steel Fibres Reinforcement Concrete Beams in Chloride Environment Combined with Inhibitor
}

\author{
AbdelMonem Masmoudi ${ }^{1}$ and Jamel Bouaziz ${ }^{2}$ \\ ${ }^{1}$ Department of Civil Engineering, LA2MP Laboratory, ENIS, Université de Sfax, Sfax, Tunisia \\ ${ }^{2}$ Department of Industrial Chemistry, National School of Engineers of Sfax, Sfax, Tunisia \\ Correspondence should be addressed to AbdelMonem Masmoudi; abdelmonem.masmoudi@enis.rnu.tn
}

Received 17 February 2016; Accepted 15 June 2016

Academic Editor: Velu Saraswathy

Copyright (C) 2016 A. Masmoudi and J. Bouaziz. This is an open access article distributed under the Creative Commons Attribution License, which permits unrestricted use, distribution, and reproduction in any medium, provided the original work is properly cited.

\begin{abstract}
This paper presented the effect of the combination of an inhibitor and steel fibre reinforced concrete (SFRC) for concrete structures in chloride environments. Twelve beams were cast and tested to study their flexural behavior. The morphology of steel surfaces using the inhibitor after observing the scanning electron microscope showed a low layer of corrosion products. The steel surface immersed in the inhibitor free solution was seen to have been subject to chloride ions attacks as shown in this study. The interest to the field of the present study is the relatively higher durability of the performance when using the inhibitor. Crack width and crack spacing for beams under the same load showed that the use of SFRC with the inhibitor for concrete structures in chloride environments must have transferred tension across cracks that led to reducing crack spacing without any chloride ions attack.
\end{abstract}

\section{Introduction}

When the concrete is exposed to seawater or deicing salts, it tends to cause localised breakdown of the passive film, a phenomenon termed pitting corrosion. This can result in serious local loss of the bars' cross section in the affected regions while the surrounding regions remain virtually unaffected, if sufficient water and oxygen are available at the reinforcement surface.

According to a study carried out by Beeby [1] and Tuutti [2], results showed that macrocracks play an important role in the transport of aggressive substances. If engineers would significantly improve the life span of concrete structures they must be controlling these cracks. As a way to ensure the durability of the reinforced concrete structures, current regulations define the maximum allowed crack widths, based on exposure conditions. Even though the effect of cracks on the initiation of corrosion has been dealt with by several authors, the effect of cracks on durability, for example, is still debated. The only consensus amongst researchers is that if the cracks exceed a certain size, they will have a negative impact on durability. Berrocal et al. [3] and Otieno et al. [4] showed that the application of steel fibre reinforced concrete (SFRC) is still limited to industrial floors, slabs, and pavements, because of the random distribution and orientation of the fibres, which reduce the mechanical efficiency when compared to conventional reinforcing bars.

Since the first studies on SFRC in the early 1960s, a significant amount of research has been carried out to achieve a deeper understanding of the mechanical properties of the material. The important result is that cracks can be modified by correct reinforced concrete members in direct tension. Another study done by Abrishami and Mitchell [5] focused on the influence of steel fibres on reinforcement concrete beams indicated that the transverse cracks were more closely and smaller compared with specimens without steel fibres. This leads to the fact that adding fibres could effectively control splitting cracks. In a similar study concluded on the SFRC uses by Bischoff [6], it was showed that SFRC is efficient in transferring tension across cracks, consequently reducing crack spacing and increasing tension stiffening. The influence of adding different types of steel fibres on chloride penetration has been studied by Mangat and Gurusamy [7] and discussed elsewhere by Buratti et al. [8]. They found that fibres had an insignificant effect in sound concrete. In addition, when the structures are exposed to marine 


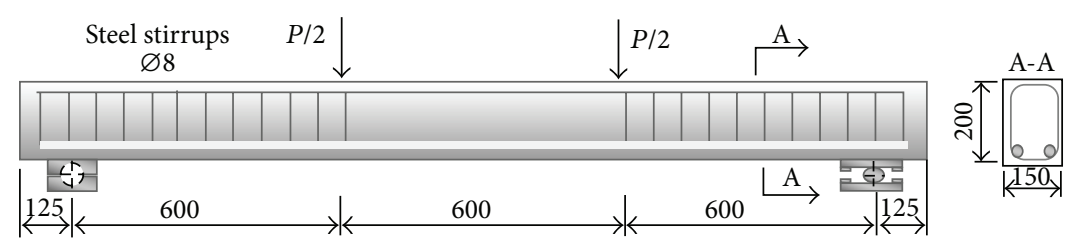

Figure 1: Geometric details of the tested beams.

environments, they do not exhibit any effects to the sound and also elements remain uncracked.

The addition of fibres for cracked concrete had a marginal effect for cracks of less than $0.2 \mathrm{~mm}$. This addition became important for cracks of more than $0.5 \mathrm{~mm}$. A critical crack width has been estimated to values ranging between 0.10 and $0.25 \mathrm{~mm}$, which showed that hybrid fibres would be very close to the concrete surface. Some researchers have directed their investigations towards the mechanical characterization when fibres are exposed to extreme environments [9]. This study makes in evidence the fact that the fibres are influenced by external agents, and, consequently, a higher degradation would be expected Danso et al. [10]. Another study carried by Hongfang [11] used a simulated impressed current cathodic protection system with $3 \% \mathrm{NaCl}$ solution without inhibitor. Experimental results showed that, during anodic polarization, the epoxy was corroded. Kobayakawa et al. [12] investigated the influence of superficial fibres accompanied by substantial stain rust appearing at the concrete surface. Results showed that reduction of damage in the fibres is the consequence of reducing the water cement ratio of the concrete mix as well as limiting the region where fibres are prone to suffering severe corrosion to depths as small as $0.2 \mathrm{~mm}[13,14]$.

The critical chloride content is generally accepted to be in the range of $0.4-1.0 \% \mathrm{Cl}^{-}$(by weight of cement) for conventional reinforced concrete structures. The critical chloride content, or chloride threshold value, represents a basic concept used today by most of the current service life models. Mangat and Gurusamy [15] showed that fibres embedded in concrete remained free from corrosion for chloride concentrations up to $1.7 \% \mathrm{Cl}^{-}$. This is in agreement with the results of Janotka et al. [16] and Ganesan et al. [17] who found that the necessary concentration of chloride to initiate corrosion in steel fibres was at least 3 times higher compared to conventional reinforcing steel.

On the other hand, the experimental investigation carried out in solutions simulating the concrete pore electrolyte by Elsener et al. [18] revealed that the amino alcohol tested compounds are efficient against steel corrosion. Moreover, their use as mortar admixtures is not detrimental to the physicomechanical properties. Triethanolamine (TEA) use at a convenient concentration equal to $0.5 \mathrm{~mL} / 50 \mathrm{~mL}$ guaranteed steel corrosion inhibition in mortar contaminated by sodium chloride $\mathrm{NaCl}$ at $0.5 \mathrm{~mole} / \mathrm{L}$. The electrochemical impedance spectroscopy technique EIS associated to periodic chloride concentration measurements proved the effect of TEA in delaying the corrosion process initiation. Furthermore, its capacity of diffusion through mortar cover was noted.
Consequently, TEA can be exploited through both preventive and curative modes of use [19-21].

This paper aimed at determining the viability of using steel bars immersed in a chloride solution combined with inhibitor to improve the relatively better durability performance.

\section{Experimental Test Program}

2.1. Beams Specifications. The beams were cast into two series with the same target concrete strength $(30 \mathrm{MPa})$. For each series, a total of 8 concrete beams of $150 \times 200 \times 2050 \mathrm{~mm}$ (Figure 1) and with a clear cover equal to $20 \mathrm{~mm}$ were with two different amounts of steel bars (two diameters $10 \mathrm{~mm}$ and two diameters $12 \mathrm{~mm}$ ) placed at the tension side (bottom). In this study, groups of beams were tested before and after being immersed for 28 days in two $\mathrm{Cl}^{-}$solutions $\left(\mathrm{S}_{1}\right.$ and $\mathrm{S}_{2}$ ). The two chloride solutions' concentrations are equal to $5.1 \% \mathrm{Cl}^{-}$(three times the minimum value likely to cause corrosion for the steel fibres which is around $1.7 \% \mathrm{Cl}^{-}$). The solution $\mathrm{S}_{2}$ having the same chloride concentration $(5.1 \%$ $\mathrm{Cl}^{-}$) is combined with triethanolamine (TEA) type inhibitor. Changes in capacity flexure behavior values are often used as indicators of the durability performance. Additionally, for comparison purposes, 2 beams were reinforced with $2 \varnothing 10$ steel bars and 2 beams were reinforced with $2 \varnothing 10$ steel bars and steel fibre reinforcement thus having a similar stiffness as the other beams that were immersed for 28 days in water $\left(\mathrm{L}_{\mathrm{o}}\right.$ equal zero $\% \mathrm{Cl}^{-}$).

The beams were designated as Sx-Myyz, where $S$ denotes the chloride solution $\left(\mathrm{S}_{1}, \mathrm{~S}_{2}\right)$, respectively, combined with inhibitor and not combined. For comparison purposes, a reference solution $\mathrm{S}_{\mathrm{o}}$ without chloride nor inhibitor was chosen; $\mathrm{M}$ is the material of reinforcement $(\mathrm{S}=$ Stell, SSF = steel with steel fibres) and yy is the diameter of the bar (10, $12 \mathrm{~mm}$ ); additionally, $z$ differentiates between the twin beams. The geometry and designation of the beams are shown in Figure 1 and Table 1.

\subsection{Material Properties}

2.2.1. Concrete. Concrete with a target $30 \mathrm{MPa}$ was used for both beam series, " $\mathrm{S}_{1}$ " and " $\mathrm{S}_{2}$." The concrete was provided by a local ready-mix supplier with a maximum aggregate size of $12 \mathrm{~mm}$. The proportions of the concrete mix are summarized in Table 2. For both series, the cylindrical specimens were kept in the same exposure conditions of temperature and humidity until testing. From these cylinders the compressive strength $f_{c}$, compressive modulus of elasticity $E_{c}$, and tensile 
TABLE 1: Beams designation.

\begin{tabular}{|c|c|c|c|c|}
\hline Beam designation & Rebar material & $\varnothing \operatorname{bar}(\mathrm{mm})$ & Reinforcement ratio $\rho(\%)$ & Concentrations of $\mathrm{Cl}^{-}(\%)$ \\
\hline \multicolumn{5}{|l|}{ S-beams } \\
\hline$S_{1}-S_{10 a}$ & Steel & 10 & 1.0 & 5.1 \\
\hline$S_{1}-S_{10 b}$ & Steel & 10 & 1.0 & 5.1 \\
\hline $\mathrm{S}_{2}-\mathrm{S}_{12 \mathrm{a}}$ & Steel & 12 & 1.4 & $5.1+$ TEA \\
\hline $\mathrm{S}_{2}-\mathrm{S}_{12 \mathrm{~b}}$ & Steel & 12 & 1.4 & $5.1+$ TEA \\
\hline $\mathrm{S}_{1}-\mathrm{SSF}_{10 \mathrm{a}}$ & Steel + steel fibres & 10 & 1.0 & 5.1 \\
\hline $\mathrm{S}_{1}-\mathrm{SSF}_{10 \mathrm{~b}}$ & Steel + steel fibres & 10 & 1.0 & 5.1 \\
\hline $\mathrm{S}_{2}-\mathrm{SSF}_{12 \mathrm{a}}$ & Steel + steel fibres & 12 & 1.4 & $5.1+$ TEA \\
\hline $\mathrm{S}_{2}-\mathrm{SSF}_{12 \mathrm{~b}}$ & Steel + steel fibres & 12 & 1.4 & $5.1+$ TEA \\
\hline $\mathrm{S}_{\mathrm{o}}-\mathrm{S}_{10 \mathrm{a}}$ & Steel & 10 & 1.0 & 0 \\
\hline $\mathrm{S}_{\mathrm{o}}-\mathrm{S}_{10 \mathrm{~b}}$ & Steel & 10 & 1.0 & 0 \\
\hline $\mathrm{S}_{\mathrm{o}}-\mathrm{SSF}_{10 \mathrm{a}}$ & Steel + steel fibres & 10 & 1.0 & 0 \\
\hline $\mathrm{S}_{\mathrm{o}}-\mathrm{SSF}_{10 \mathrm{~b}}$ & Steel + steel fibres & 10 & 1.0 & 0 \\
\hline
\end{tabular}

TABLE 2: Composition of concrete.

\begin{tabular}{lcc}
\hline Component & Units & Concrete mix \\
\hline Water & $\mathrm{Kg} / \mathrm{m}^{3}$ & 175 \\
Cement (CEMI 32.5 N) & $\mathrm{Kg} / \mathrm{m}^{3}$ & 350 \\
w/c ratio & & 0.51 \\
Fine aggregate & $\mathrm{Kg} / \mathrm{m}^{3}$ & 900 \\
Coarse aggregate & $\mathrm{Kg} / \mathrm{m}^{3}$ & 820 \\
Plasticizer BV 40 & Cement weight (\%) & 1.2 \\
Target compressive strength & $\mathrm{MPa}$ & 30 \\
\hline
\end{tabular}

strength $f_{c t}$ were evaluated and the test results are represented in Table 3.

2.2.2. Rebars. The steel bars used in these experiments were of HA 400 type, with specified design modulus of elasticity of $200 \mathrm{GPa}$ and characteristic yield and tensile strengths of $400 \mathrm{MPa}$ and $420 \mathrm{MPa}$, respectively.

2.2.3. Steel Fibres. The steel fibres used in these experiments were with specified design modulus of elasticity of $210 \mathrm{GPa}$ and characteristic yield and tensile strengths of $1000 \mathrm{MPa}$ and $1150 \mathrm{MPa}$, respectively.

2.2.4. Triethanolamine. The inhibitor (TEA) used in conditioning beams has a convenient concentration equal to $0.5 \mathrm{~mL} / 50 \mathrm{~mL}$ of water.

2.3. Test Setup and Instrumentation. All beam specimens were tested under a static four-point load test. A servocontrolled hydraulic machine with a capacity of $300 \mathrm{kN}$ was used to apply the load to the test beam (Figure 2). The load was applied in displacement control mode at a displacement rate of $0.7 \mathrm{~mm} / \mathrm{min}$, and all data were collected by a data acquisition system. The test was stopped every $10-20 \mathrm{kN}$ to register the evolution of cracks, and crack widths were

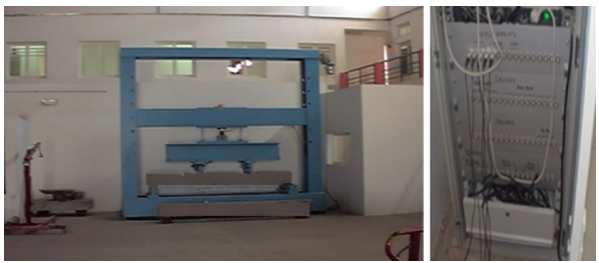

Figure 2: Flexure test with data acquisition system.

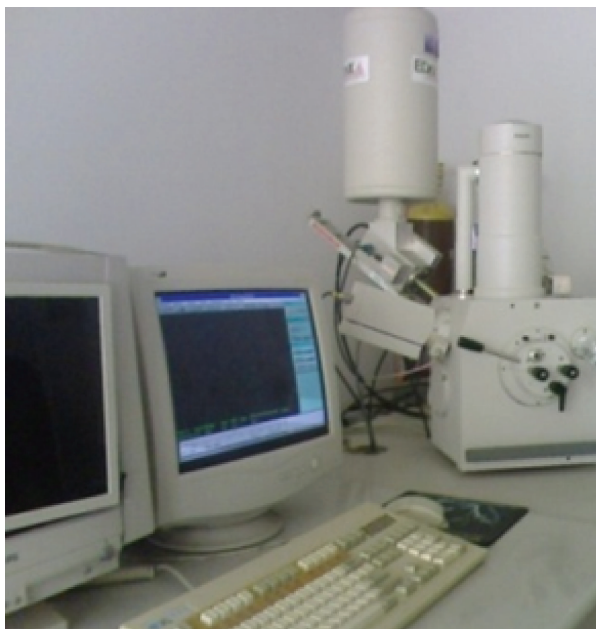

FIGURE 3: Philips XL 30 SEM.

measured with an optical micrometer with an accuracy of $0.05 \mathrm{~mm}$.

Scanning electron microscope (SEM) observations and image analyses were performed to observe the specimens microstructure before and after immersion in the chloride environment. All specimens observed in the SEM were first cut, polished, and coated with a thin gold layer. After the coating of surfaces, microstructural observations were performed on a Philips XL 30 SEM (Figure 3). 
TABLE 3: Experimental values of $f_{c}, E_{c}$, and $f_{c t}$.

\begin{tabular}{|c|c|c|c|c|c|}
\hline \multicolumn{2}{|c|}{ Compressive strength $\left(f_{c}\right)$} & \multicolumn{2}{|c|}{ Compressive modulus of elasticity $\left(E_{c}\right)$} & \multicolumn{2}{|c|}{ Tensile strength $\left(f_{c t}\right)$} \\
\hline Age (days) & Mean (MPa) & Age (days) & Mean (MPa) & Age (days) & Mean $(\mathrm{MPa})$ \\
\hline 31 & 32.1 & 31 & 34125 & 31 & 2.8 \\
\hline
\end{tabular}

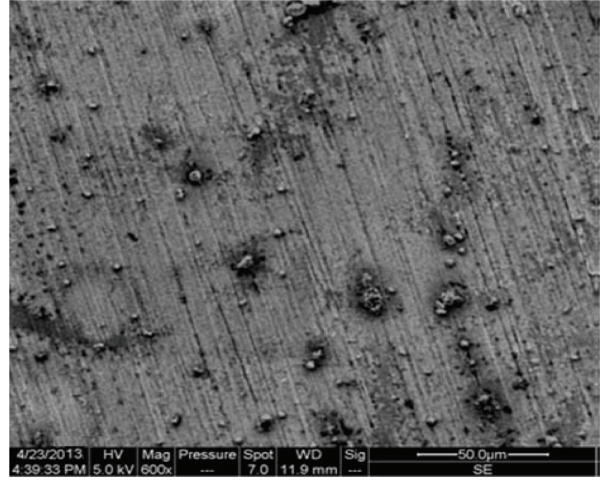

(a)

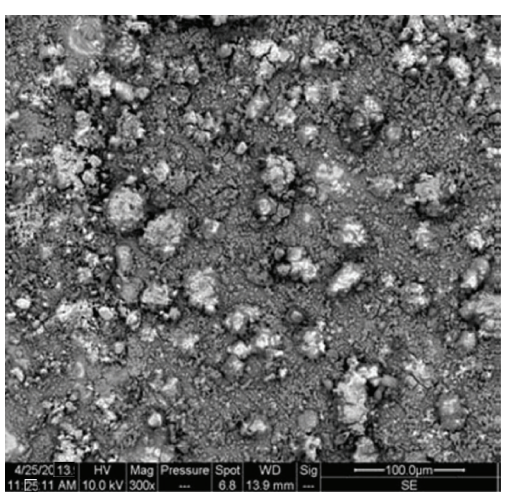

(b)

FIGURE 4: SEM images of steel bars imbedded in chloride. (a) Using an inhibitor; (b) without any inhibitor.

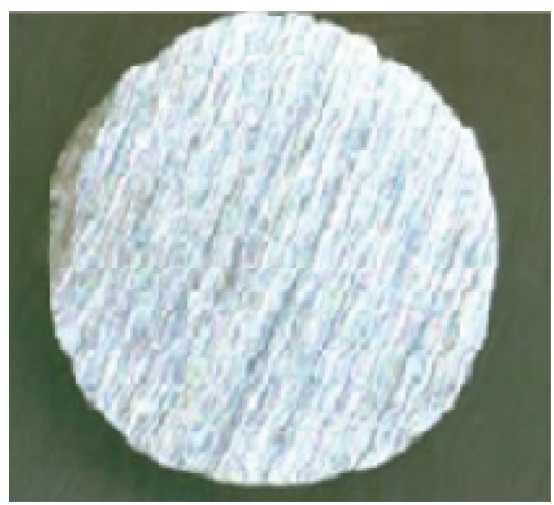

(a)

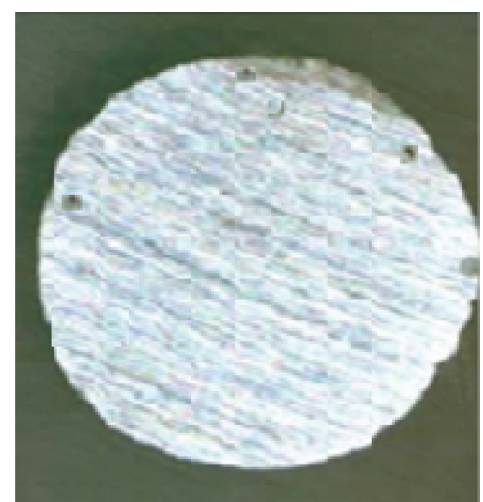

(b)

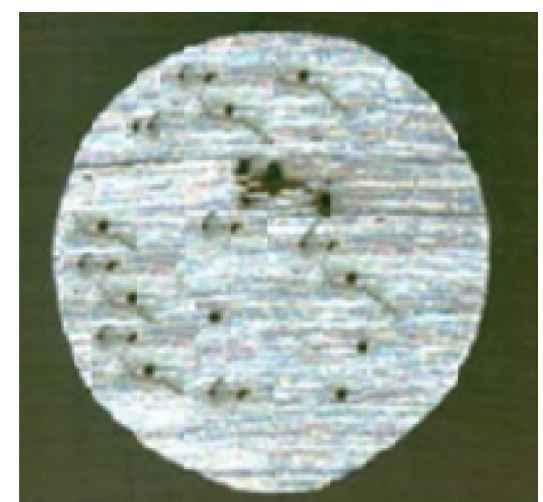

(c)

FIGURE 5: Micrographs of steel surfaces immersed for 30 days in different environments (a) $S_{o}$, (b) $S_{1}$, and (c) $S_{2}$.

\section{Test Results and Discussion}

3.1. Microstructure Evaluations. Figure 4 shows the morphology of steel surfaces after observing the scanning electron microscope (SEM) at the end of immersion in solutions $S_{1}$ and $\mathrm{S}_{2}$. The steel surface immersed in the solution using inhibitor (Figure 4(a)) has a low layer of corrosion products, while the steel surface immersed in the solution without inhibitor (Figure 4(b)) clearly shows the attack of steel surface by chloride ions. Chloride ions are responsible for corrosion, resulting in the decrease of the steel bar section.

The microstructure comparisons of the two SEM bars revealed that bars immersed in inhibitor solutions had relatively better durability performance, which is in agreement with the results of Avci [19], revealing that the inhibitor used in conditioning with a convenient concentration equal to
$0.5 \mathrm{~mL} / 50 \mathrm{~mL}$ of water is efficient against steel corrosion. This highlights the protective effect of the inhibitor (TEA).

A comparison of the micrographs steel surfaces immersed in three different solutions levels $S_{0}, S_{1}$, and $\mathrm{S}_{2}$, showed clearly that there is no attack of the steel surfaces immersed in solution $\mathrm{S}_{\mathrm{o}}$ (Figure 5(a)). No significant attack was observed for the steel surfaces immersed in the solution $S_{1}$. However the steel surfaces in the solution $S_{2}$ show considerable attack by chloride ions. It can be concluded that the necessary concentration of chloride to initiate corrosion in SFRC combined with an inhibitor was at least 4 times higher compared to the conventional reinforcing steel.

Concrete mortar samples cut from specimens with and without TEA $(0.5 \mathrm{~mL} / 50 \mathrm{~mL})$ and having been treated for 28 days in water have been observed in SEM (Figure 6). The comparison of two figures (Figures 6(a) and 6(b)) reveals that 


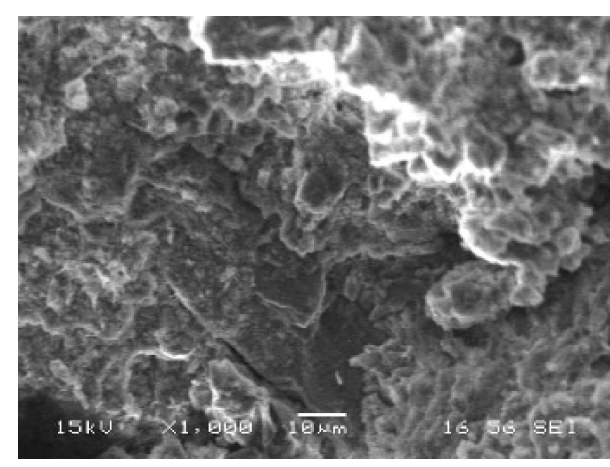

(a)

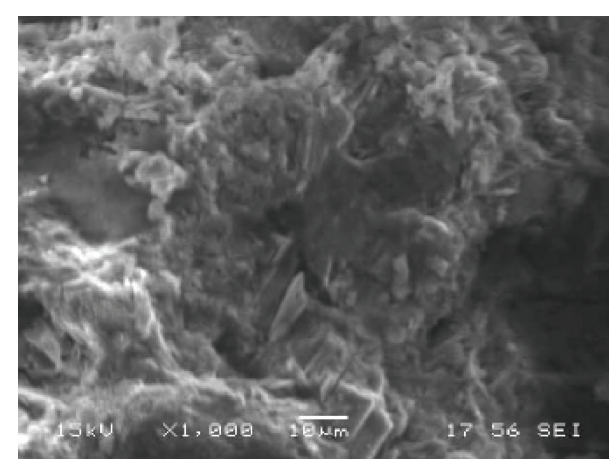

(b)

FIGURE 6: SEM micrographs mortar sample. (a) Without an inhibitor; (b) with any inhibitor.

Load $=45.3 \mathrm{kN}$

Av. crack width $=0.8 \mathrm{~mm}$

Failure due to concrete crushing at load $=81.2 \mathrm{kN}$

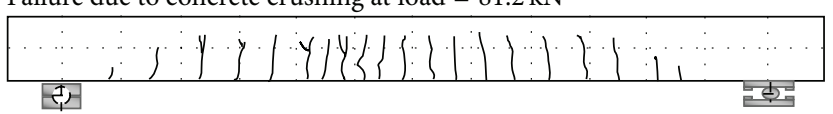

(a)
Load $=45.2 \mathrm{kN}$

Av. crack width $=0.35 \mathrm{~mm}$

Failure due to concrete crushing at load $=95.4 \mathrm{kN}$

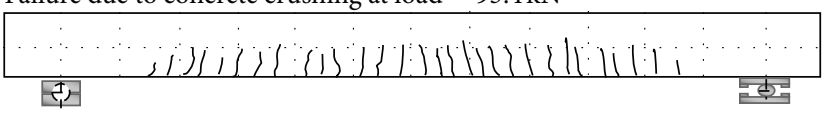

(b)

Load $=45.3 \mathrm{kN}$

Av. crack width $=0.24 \mathrm{~mm}$

Failure due to concrete crushing at load $=96.8 \mathrm{kN}$

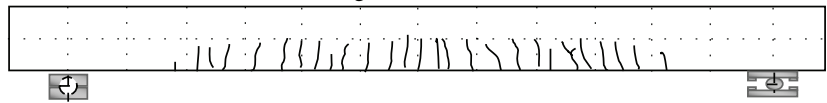

(c)

FIGURE 7: Crack pattern for beams under same load. (a) Without SFRC, (b) with SFRC, and (c) with SFRC and an inhibitor.

the morphology of concrete mortar was not modified by the incorporation of the TEA inhibitor.

3.2. Results on Cracking. In Figure 7, the typical experimental crack widths are represented as a function of the average crack width at same load step for two specimens with and without steel fibre reinforced concrete (SFRC). As depicted, during the crack formation phase, cracks form at random positions and are mostly vertical and start at the central zone. As the load increases, additional inclined cracks appear due to the effect of shear forces on the principal tensile stresses, and those that were vertical at the shear span also start to incline because of the combined flexural-shear effects in the zones with larger bending moment.

Under the same load, crack pattern for beams showed that the use of SFRC should transfer tension across cracks which led to reducing crack spacing $(0.35 \mathrm{~mm}$ compared to $0.8 \mathrm{~mm})$ and increased tension stiffening (Figure 7(b)). The transverse cracks were smaller and more closely spaced compared to beams without steel fibres. Finally, no more cracks appeared and the existing ones widened. The experimental minimum, average, and maximum crack spacing were measured, at the same load steps, in the pure bending central zone at the height of the reinforcement. The crack spacing ranged between $30 \mathrm{~mm}$ and $190 \mathrm{~mm}$ for beams without SFRC. However crack spacing ranged between $14 \mathrm{~mm}$ and $85 \mathrm{~mm}$ for beams with SFRC. This may lead us to conclude that the fibres provide good distribution of cracks, resulting in a reduction of the crack opening. The load level $P$ at which cracking stabilized $\left(P_{\text {sta }}\right)$ ranged between $12 \%$ and $43.1 \%$ of the ultimate load $\mathrm{Pu}$, with a mean value of $25.1 \% \mathrm{Pu}$ and a standard deviation of 9.3\% Pu for beams without SFRC. This load level $P$ rose for beams with SFRC, and $P_{\text {sta }}$ ranged between $19 \%$ and $63.1 \%$ of the ultimate load $\mathrm{Pu}$, with a mean value of $41.05 \% \mathrm{Pu}$ and a standard deviation of $9.7 \% \mathrm{Pu}$. For the same load, the average crack width for beams with the inhibitor is less that those conditioning in solution without inhibitor. The inhibitor changes the behavior and protects structure in chloride environments. The interest to the field of using the SFRC combined with an inhibitor in RC beams in chloride environments has the positive impact of reducing the crack width and therefore increasing the durability of the structure (Figure 7(b)).

\section{Conclusion}

Based on the experimental study and microstructure observations, the following conclusions can be drawn:

(i) The microstructure for the two SEM bars revealed that bars immersed in a chloride solution combined 
with an inhibitor had relatively better durability performance.

(ii) The necessary concentration of chloride to initiate corrosion in SFRC combined with an inhibitor is at least 3 times higher compared to conventional reinforcing steel.

(iii) Steel fibres combined with an inhibitor could be used in reinforced concrete structures exposed to chloride environments improving their overall durability performance

(iv) The use of SFRC should transfer tension across cracks leading to reduced crack spacing and the inhibitor changes the behavior and protects structure in chloride environments.

(v) The average crack width for beams with an inhibitor is less that conditioning in solution without any inhibitor.

\section{Competing Interests}

The authors declare that there is no conflict of interests.

\section{Acknowledgments}

The authors would like to thank the manufacturer of el Fouled at Bizerte for providing the steel bars and the Faculty of Sciences of Sfax for using Philips XL 30 SEM. The research was conducted in National Engineering School of Sfax.

\section{References}

[1] A. W. Beeby, "Cracking: what are crack width limits for?" Concrete, vol. 12, no. 7, pp. 31-33, 1978.

[2] K. Tuutti, "Corrosion of steel in concrete," CBI Report 4:82, The Swedish Cement and Concrete Research Institute, Stockholm, Sweden, 1982.

[3] C. Berrocal, K. Lundgren, and I. Lofgren, "Influence of steel fibers on corrosion of reinforcement in concrete in chloride environments: a review Fibre concrete," in Proceedings of the 7th International Conference (FIBRE CONCRETE '13), Prague, Czech Republic, September 2013.

[4] M. B. Otieno, M. G. Alexander, and H.-D. Beushausen, "Corrosion in cracked and uncracked concrete-influence of crack width, concrete quality and crack reopening," Magazine of Concrete Research, vol. 62, no. 6, pp. 393-404, 2010.

[5] H. H. Abrishami and D. Mitchell, "Influence of steel fibers on tension stiffening," ACI Structural Journal, vol. 94, no. 6, pp. 769-776, 1997.

[6] P. H. Bischoff, "Tension stiffening and cracking of steel fiberreinforced concrete," Journal of Materials in Civil Engineering, vol. 15, no. 2, pp. 174-182, 2003.

[7] P. S. Mangat and K. Gurusamy, "Chloride diffusion in steel fibre reinforced marine concrete," Cement and Concrete Research, vol. 17, no. 3, pp. 385-396, 1987.

[8] N. Buratti, C. Mazzotti, and M. Savoia, Long-Term Behavior of Cracked SFRC Elements Exposed to Chloride Solutions, ACI Special Publication, 2011.
[9] J.-L. Granju and S. U. Balouch, "Corrosion of steel fibre reinforced concrete from the cracks," Cement and Concrete Research, vol. 35, no. 3, pp. 572-577, 2005.

[10] H. Danso, D. Brett Martinsona, M. Ali, and J. B. Williams, "Physical, mechanical and durability properties of soil building blocks reinforced with natural fibres," Construction and Building Materials, vol. 101, part 1, pp. 797-809, 2015.

[11] S. Hongfang, "Corrosion behavior of carbon reinforced polymer anode in simulated impressed current cathodic protection system with $3 \% \mathrm{NaCl}$ solution," Construction and Building Materials, vol. 112, pp. 539-546, 2016.

[12] A. Kobayakawa, D. Homma, H. Mihashi, and K. Shimozawa, "Corrosion durability of fiber reinforced cementitious composites," in Proceedings of the 2nd RILEM Workshop on Concrete Durability and Service Life Planning, pp. 311-318, 2009.

[13] K. Kosa and A. E. Naaman, "Corrosion of steel fiber reinforced concrete," ACI Materials Journal, vol. 87, no. 1, pp. 27-37, 1990.

[14] S. U. Balouch, J. P. Forth, and J.-L. Granju, "Surface corrosion of steel fibre reinforced concrete," Cement and Concrete Research, vol. 40, no. 3, pp. 410-414, 2010.

[15] P. S. Mangat and K. Gurusamy, "Permissible crack widths in steel fibre reinforced marine concrete," Materials and Structures, vol. 20, no. 5, pp. 338-347, 1987.

[16] I. Janotka, L'. Krajčí, K. Komloš, and D. Frt’alová, “Chloride corrosion of steel fibre reinforcement in cement mortar," The International Journal of Cement Composites and Lightweight Concrete, vol. 11, no. 4, pp. 221-228, 1989.

[17] N. Ganesan, R. Abraham, and S. Deepa Raj, "Durability characteristics of steel fibre reinforced geopolymer concrete," Construction and Building Materials, vol. 93, pp. 471-476, 2015.

[18] B. Elsener, M. Büchler, F. Stalder, and H. Böhni, "Migrating corrosion inhibitor blend for reinforced concrete: part 1prevention of corrosion," Corrosion, vol. 55, no. 12, pp. 1155-1163, 1999.

[19] G. Avci, "Inhibitor effect of $N, N$-methylenediacrylamide on corrosion behavior of mild steel in $0.5 \mathrm{M} \mathrm{HCl}$," Materials Chemistry and Physics, vol. 112, no. 1, pp. 234-238, 2008.

[20] V. Afroughsabet and T. Ozbakkaloglu, "Mechanical and durability properties of high-strength concrete containing steel and polypropylene fibers," Construction and Building Materials, vol. 94, pp. 73-82, 2015.

[21] B. Elsener, Corrosion Inhibitors for Steel in Concrete. State of the Art Report, EFC Series no. 33, IOM Communications, Institute of Materials, London, UK, 2001. 

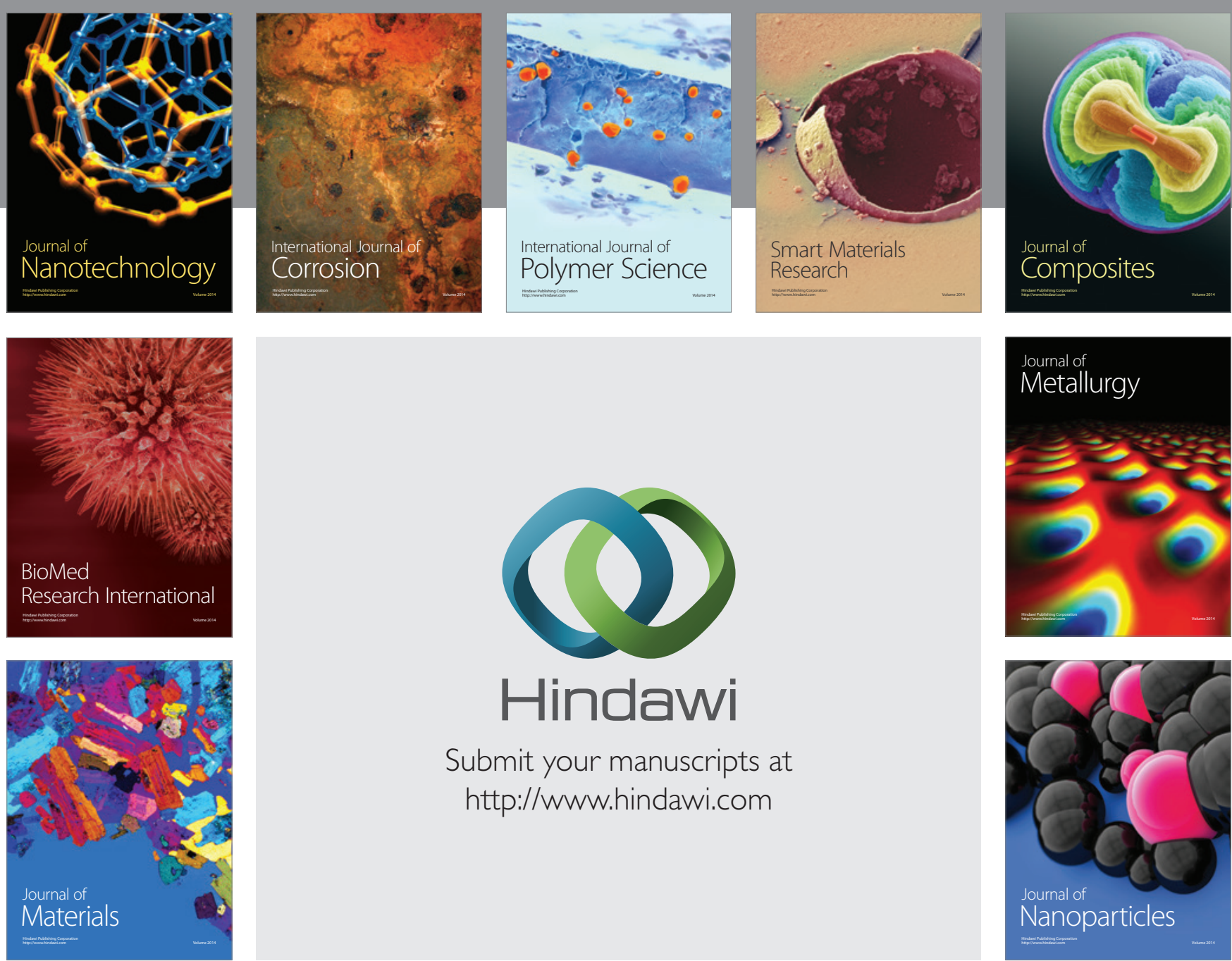

\section{Hindawi}

Submit your manuscripts at

http://www.hindawi.com

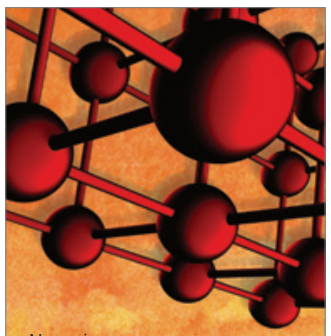

Materials Science and Engineering
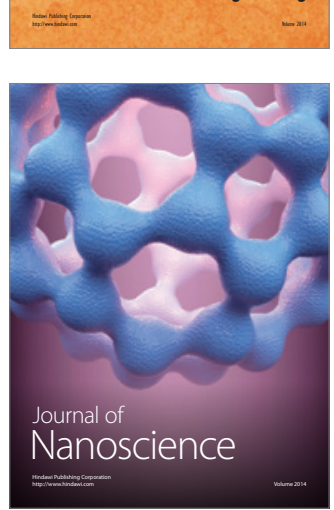
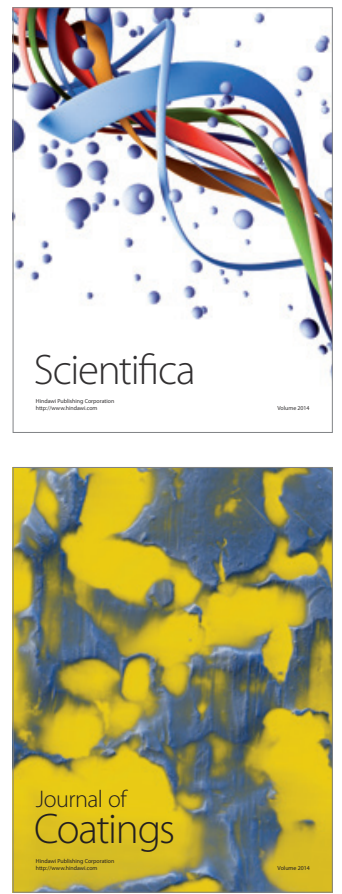
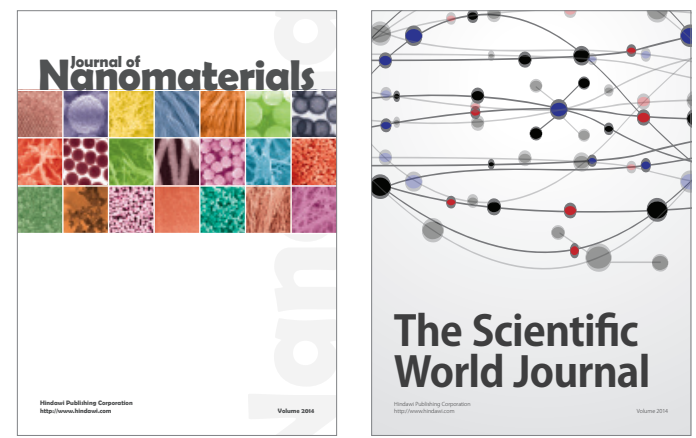

The Scientific World Journal
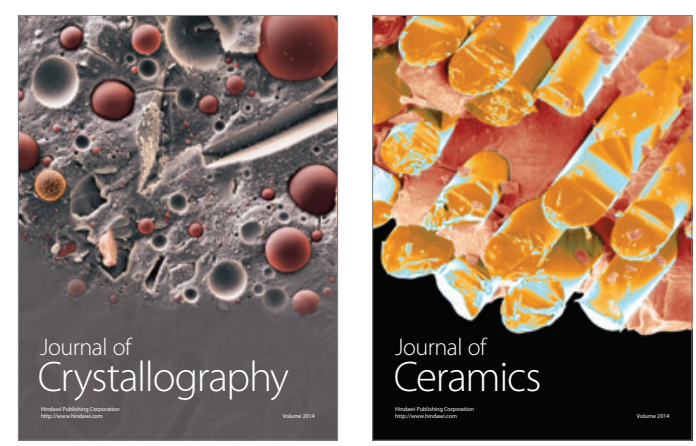
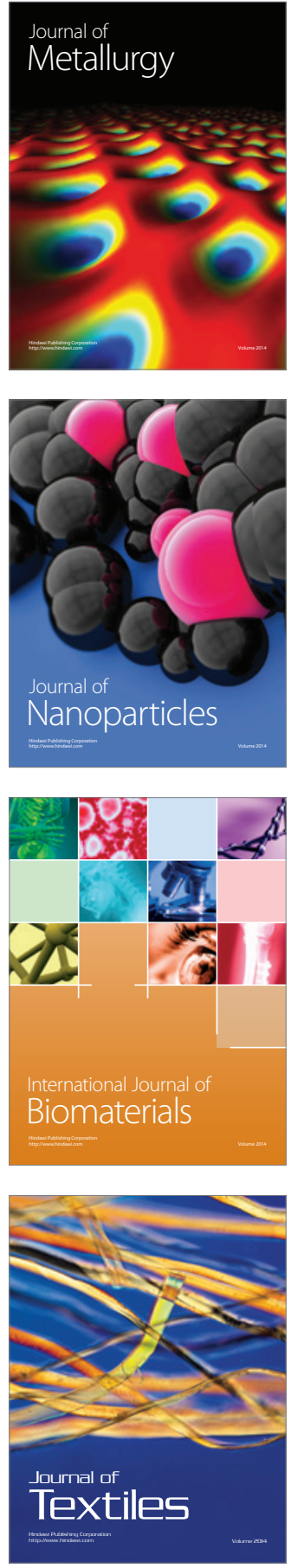